\title{
EDUCATION AND INTERNATIONALISATION
}

\author{
QUALITY ASSURANCE AND THE RATIONALE \\ BEHIND INTERNATIONALISATION. THE CASE \\ OF ESB BUSINESS SCHOOL, REUTLINGEN \\ UNIVERSITY
}

JeL CLASSifications: M10

\author{
Hazel Gruenewald \\ ESB Business School, \\ Reutlingen University, Deutschland
}

KEYWORDS: Internationalisation, quality, assurance, mission-driven, accreditation

ABSTRACT: Any business school striving for AACSB international accreditation will be aware of the importance that the organisation attaches to mission-driven standards. Schools are expected to demonstrate a deeper understanding of what makes them distinctive. This paper presents the current challenges faced at ESB Business School, one of Germany's most international business schools, in terms of internationalisation. What we believe to be distinctive about our offering is its international character, a notion considered by many no longer to be a differentiator. The school's focus on innovation and sustainability with respect to internationalisation is shown, however, to be an important differentiator from the "shorttermism" and "herd behaviour" demonstrated by numerous higher education institutions which react to a perceived pressure through globalisation to go international.

http://dx.doi.org/10.15208/pieb.2014.03

Vol.14 (1), PP.28-33

Source: Gruenewald H., 2014. "Quality assurance and the rationale behind internationalisation. The case of ESB Business School, Reutlingen University," Perspectives of Innovations, Economics \& Business,

Vol.14(1), pp.28-33, http://dx.doi.org/10.15208/pieb.2014.03

\section{Introduction}

Any business school striving for AACSB international accreditation will be aware of the importance that the organisation attaches to mission-driven standards. Schools are expected to demonstrate a deeper understanding of what makes them distinctive. This paper aims to present the current challenges we face at ESB Business School, one of Germany's most international business schools, with respect to this issue,

So, why should internationalisation pose us with a dilemma? Well, it appears that these days the notion is no longer considered a differentiator. In her article, Five myths about internationalization, Jane Knight of the University of Toronto, explains how internationalisation is no longer "flavour of the month", but rather a standard part of institutional mission statements, policies, and strategies and national policy frameworks (Knight, 2011). According to Knight, internationalisation nowadays is

${ }^{1}$ The article was reported at IHE-2013 conference "Internationalisation in Higher Education: Evaluating concepts, challenges and strategies," Prague, Czech Republic

- 28 -

corresponding email: hazel(dot)gruenewald[at]reutlingen-university(dot)de

postal address: ESB Business School, Reutlingen University,

Alteburgstraße 150, 72762 Reutlingen, Germany 
"used to describe anything and everything remotely linked to worldwide, intercultural, global, or international. In short, it is a catchall phrase and losing its meaning and direction" (p.14).

Knight is not alone in her criticism of current higher education trends in internationalisation. Uwe Brandenburg of the Centre for Higher Education Development and Hans de Wit, professor of internationalisation at the School of Economics and Management, Hogeschool van Amsterdam write in their article, dramatically titled "The end of internationalisation":

Gradually, the "why and wherefore" have been taken over by the way internationalization has become the main objective: more exchange, more degree mobility, and more recruitment. Even the alternative movement of "internationalization at home" of the late 1990s has shifted rapidly into this instrumental mood (Brandenburg and de Wit, 2011).

Another open sceptic of certain developments in internationalisation in higher education over recent decades is Dieter Lenzen, Vice-President of the German Rectors' Conference for international affairs (HRK) ${ }^{2}$. His most outspoken comments are directed at attempts to quantify degrees of internationalisation using easily measurable indicators such as percentages of incoming or outgoing students. Lenzen does not dispute the value of such indicators and KPIs for benchmarking purposes or as a means of determining an institution's position or standing with respect to particular international activities. He points out, however, the limitations of such figures with respect to painting a true picture of reality. In his opinion, a sustainable process should take into account qualitative aspects within the context of the institution's own goals and capacities.

The need to differentiate is of utmost importance in today's world of tertiary education. Universities compete to get a greater share in the global education market, to be listed higher in world rankings and to be internationally accredited. Yet, in the race to be more international, clearly too few institutions ask themselves honestly what they want to achieve with greater internationalisation or how their goals tally with the challenges that internationalisation and globalisation pose. The realities of large multicultural lecture halls and seminar rooms, English as the lingua franca, integration issues, different national education standards and expectations are just some of the challenges arising from efforts to increase the intake of foreign students or the percentage of international faculty. Only once targets have been achieved do some institutions realise how off the mark they are concerning quality matters.

This paper outlines the importance of critical self-reflection when seeking to develop meaningful internationalisation goals. It presents the benefits of a balanced approach with respect to setting quantitative and qualitative goals. Finally, it underlines the crucial role of quality management in helping to achieve sustainability and present clear outcome measures with respect to internationalisation. The emphasis on

2 In his opening of a symposium organised by the German Rectors' conference (HRK) on the topic of successful internationalisation (Bonn, 11-12 November, 2012), Lenzen reaffirmed claims that internationalisation has become a standard part of university mission statements, at least with respect to Germany. HRK Symposium - Erfolgreich internationalisieren! Internationalität von Hochschulen erheben, bewerten und weiterentwickeln. 11 - 12 December 2012. Bonn, Germany 
innovation and sustainability is an important means for schools to differentiate themselves from what has been branded "short-termism" and "herd behaviour" resulting from a perceived pressure through globalisation to go international (Thomas, Thomas and Wilson, 2013).

\section{Section A}

ESB Business School has built its reputation on its international orientation. It is currently the largest school of state-run Reutlingen University ${ }^{3}$. Regular surveys among applicants, students, alumni, industrial partners etc. asking what they find most attractive about the school frequently refer to our international orientation. By way of background information, the business school was undertaking considerable internationalisation activities in the 1970s and 1980s at a time when these did not carry the prestige associated with such actions today.

1979 marked the beginning of ESB Business School's first double degree. In the meantime the school has 12 such integrated programmes with partners in the UK, Ireland, US, France, Mexico, Poland, Italy, Holland and Spain. With seven other leading business schools in Europe and America, it has established the largest fully integrated university consortium of business schools in Europe. Partners in the socalled IPBS (International Partnership of Business Schools) network consult and meet regularly to discuss issues related to their specific programmes and general developments in management education. In addition to offering bachelor and master degree programmes, the IPBS network also draws from its extensive pool of professors to provide opportunities for research collaboration, including doctoral studies. The pioneering efforts of colleagues in this area helped establish and gain acceptance for double degree programmes in Germany.

If international outreach then is a significant reason for attracting and satisfying our customers and keeping other stakeholders happy, it makes little business sense to pave out a new strategy, just because being international is "nothing new". Yet, the question remains: how can we distinguish ourselves from those many other business schools that have jumped onto the internationalisation bandwagon? The answer for us lies in our commitment to quality management. ESB Business School arose from the merger of three different schools, with differing strategies. The decision to pursue institutional and international accreditation has helped us gain a sense of common vision and direction, crucial in a large school. Moreover, our quality management system has led to greater internal transparency and increased awareness and exchange of good practices. Our recipe for innovation is not about reinventing the wheel, but rather seeks opportunities to transfer successful business models, benefit from synergies and find ways of creating sustainable models for the future.

As previously mentioned, ESB Business School is particularly renowned in Germany for co-founding an international network of business schools which share a common purpose and regularly confer to ensure that their programmes adhere to the highest quality standards. A future goal is to leverage expertise in this area to create a federation of business schools in the field of business engineering. Another aim with regard to internationalisation is to focus on strategic partnerships. This has involved the introduction of a stringent selection procedure for the establishment of new partner cooperation agreements. The purpose is to assess the overall significance of a

${ }^{3}$ The university was awarded the prize for being Germany's International University in 2010 by the German Academic Exchange Service (Deutscher Akademischer Austauschdienst) and the Stifterverband für die Deutsche Wissenschaft

- 30 -

International \& Open Access Cross-Industry Journal 
partnership for the school, as well as the potential for extending any given agreement to more than one study programme.

Accreditation by definition calls for internal reflection by means of self-assessment and benchmarking. Pursuit of programme, institutional and international accreditation has prompted us to question, check and monitor our activities. Where necessary, we have optimised or redefined new steps and directions. As ESB Business School reflected on its current strategy, here are a few of the critical questions that were asked:

1. What is our motivation behind our goals? In other words, not only what do we want to achieve, but why?

2. What stakeholder needs does our internationalisation strategy aim to meet?

3. How do we seek to achieve our targets?

4. How can we ensure that we maintain the high quality of education and service that people associate with our name while trying to become more international?

The school's vision and mission statement are strongly driven by the school's international strategy. The ambitious content and audacious use of a superlative could certainly instil the fear that the school is pursuing the current inflationary trend in internationalisation.

ESB Business School is committed to upholding its tradition in providing outstanding international, practice-oriented education and professional training as well as applied research.

Guided by the values of respect, trust, responsibility and commitment, ESB Business School as part of state-funded Reutlingen University, strives to be distinctive by becoming the most international business school in Germany by 2017 and in its offer of highly attractive programmes to applicants who aspire to fulfil challenging roles in companies and organisations in an international context.

Yet, rest assured a significant amount of soul-searching has been undertaken in which the "why and wherefore" of our vision and mission have been questioned. In seeking to be Germany's "most international business school in Germany by 2017", we strive for greater recognition and visibility in Germany and Europe with respect to our international orientation. Still, there is a clear understanding that internationalisation is not an end in itself: being more international does not necessarily equate with being better. Internationalisation initiatives only make sense if they meet the business and academic needs of our local and global stakeholders, a point underlined in our mission statement:

ESB Business School strives to strengthen its international orientation and the attractiveness of its academic programmes and applied research in order to meet the business and academic needs of its local and global stakeholders.

It is not enough to undertake numerous worthwhile international activities; schools have to document clearly and systematically their added value and market this externally, demonstrating the so-called outcome measures of these activities. The rationale is simple: internationalisation is a costly business in terms of time and resources. Sustainably financing activities in this field through additional funding means an institution needs to demonstrate to its stakeholders, in no uncertain terms, how they are benefiting from such activities.

\section{Section B}

At ESB Business School, we have introduced a balanced scorecard to ensure alignment of everyday operations with the school's mission and the internationalisation 
strategy. The school's mission identifies four key strategic focus areas on which it concentrates its efforts. It actively professes commitment to:

1. producing socially responsible graduates who are highly employable worldwide

2. achieving academic excellence in accordance with international quality and educational standards

3. forging strong international and sustainable partnerships

4. leveraging the international expertise of faculty to conduct innovative, relevant teaching and applied research that shapes business practice

Each of these focus areas comprises concrete targets. Some targets are quantifiable and clearly measurable; others are qualitative. Performance and goal accomplishment are tracked using a variety of KPIs and instruments. The realisation of individual goals in sum should lead to the attainment of the overall aim of the target focus area. In an attempt to guarantee quality and facilitate achievement of targets, a variety of measures and initiatives have been defined and implemented. Within the balanced scorecard individual initiatives are assigned to the different scorecard perspectives: finances, internal business processes, learning and growth, customers and markets. By operationalising the strategy in this way, we gain a clear overview of what measures are being implemented to realise our mission and with what degree of success.

Let us consider a concrete example to demonstrate what the balanced scorecard approach looks like in reality. The first strategic focus area relates to producing graduates with high global employability. In our strategic plan, we have defined 31 high-level targets. Out of these, here are some that are applicable to this strategic focus area:

1. Having a talented international student body

2. Ensuring that all curricula have international content

3. Offering sufficient courses in study programmes in a foreign language

4. Ensuring the international context and possible career opportunities for our graduates when cooperating with companies

5. [...]

Let us reflect on the first point. As far as establishing an international student body is concerned, one of our objectives is to ensure, at least, $30 \%$ intake of foreign students. To achieve this objective, attendance of international fairs and visits to international schools are necessary. International marketing initiatives need to be undertaken with a view to attracting the desired target group. Moreover, for quality assurance purposes stringent selection procedures have to be in place to ensure that students on double degree, exchange and internship programmes meet our requirements. All of these initiatives are monitored in our action plan or activity tracker.

Targets such as $30 \%$ intake of foreign students are meaningless if there is no overall rationale or clear additional value to be gained through pursuit of the goal. For this we have to return to our mission and the desire to meet our stakeholders' needs. Our goal to have an international student body can be seen as a response to industry's requirement for internationally oriented and interculturally competent graduates, as well the aspiration of many students to be qualified enough to gain a strong foothold on the international job market or to be able to operate successfully in international teams.

Establishing an international student body is not enough, we need to set international students up for success. Adequate initiatives must be in place to support and integrate them as well as provide teaching that accounts for their needs and diverse 
backgrounds. Examples range from preparatory courses, language support, buddy schemes, course counselling for incoming students, documentation in German and English, nomination of foreign student representatives to international curricula with a focus on diverse teaching methodologies, relevant learning outcomes and intercultural perspectives. A variety of instruments and indicators are deployed to measure success. Some have already been introduced while others remain in the pipeline. However, relevant KPIs include the percentage of foreign students successfully completing their degree programme or an internship in a German company, or the reported satisfaction with student support services, just to name a few.

To give further insight into how the balanced scorecard works, we need to list some more initiatives that contribute towards accomplishing the goal of producing globally employable students. By categorising them accordingly, it becomes clearer how we try to achieve a balanced approach towards internationalisation. In terms of financial perspectives, we encourage and track applications for funding of programmes such as Bachelor Plus, ${ }^{4}$ which enable students to study abroad for one semester and conduct an internship in the same country. The market and customer perspective of the scorecard generally focuses on the programmes themselves, research output and marketing. Relevant measures here include integrating high-quality international guest lectures or teaching from professors with international experience in our programmes, increasing our double degree portfolio, guaranteeing that we are marketing the successes of programmes or promoting them sufficiently via newsletters, flyers etc. The internal business processes perspective encompasses quality assurance and accreditation efforts. Finally, setting up and monitoring training measures to support faculty and staff with regard to international teaching and or support services provides an example of how we focus on learning and growth.

\section{Conclusion}

To summarise, the operationalisation of our ambitious internationalisation strategy within the framework of sound quality management and goal-tracking helps provide rationale to our stakeholders for why and how we attempt to be distinctive and provide additional value through the international orientation of our programmes. In addition, the use of a balanced scorecard to translate our internationalisation strategy into active every day measures and initiatives helps us keep tabs on our finances, track our performance or goal achievement, pay attention to the needs of our customers, ensure that we have planned sufficient resources and put into place sufficient developmental measures to keep morale high in an environment where financial incentives are modest, to say the least. Our experience so far has convinced us that fully integrating our internationalisation strategy into a quality management system makes good business sense.

\section{References}

Brandenburg, U. and de Wit, H., 2011. "The End of Internationalization," International Higher Education, No.62, pp.15-17

Knight, J., 2011. "Five Myths About Internationalization," International Higher Education, No.62, pp.14-15

Thomas, H., Thomas, L., Wilson, A., 2013. Promises fulfilled and unfulfilled in management education, EFMD management education series, Emerald Publishing Group, Bingley

\footnotetext{
${ }^{4}$ The Bachelor Plus programmes are currently funded by the DAAD, German Academic Exchange Service.
} - 33 - 